\title{
Achado Eletrocardiográfico De Um Paciente Com Padrão Wolff-Parkinson-White
}

\author{
Silveria, G.V.; Jornada, F.M.; Tornatore, A.R.; Accorsi, B.F.; \\ Apresentador: Guilherme Vilarino da Silveira
}

\section{Resumo}

Introdução: O padrão WPW ocorre nos pacientes portadores do feixe de Kent, uma via acessória que comunica diretamente átrios e ventrículos. Estima-se que a prevalência de um padrão de WPW no eletrocardiograma (ECG) é de 0,13-0,25 por cento da população geral e destes, cerca de $1 \%$ desenvolvem arritmias. Relato de caso: A.D.S, 49 anos, internou na enfermaria clínica para realizar biópsia de uma lesão ulcerosa na região maleolar direita. Segundo relato, a lesão surgira há três meses após trauma contuso na região. História patológica pregressa apontava hipertensão arterial primária há mais de dez anos, de difícil controle, e rastreamento negativo para diabetes. Não apresentava qualquer outro passado patológico. Durante internação paciente realizou ECG admissional que evidenciou a presença de intervalo PR curto e presença de onda Delta, configurando padrão WPW. Realizou a biópsia que demonstrou processo inflamatório e ausência de células neoplásicas. Após o controle adequado dos níveis tensionais e ajuste das medicações anti-hipertensivas, a paciente evoluiu com melhora na cicatrização da lesão ulcerosa e recebeu diagnostico de úlcera hipertensiva. Em relação ao achado ocasional no ECG (padrão WPW), após alta, paciente foi encaminhada para o serviço de cardiologia para acompanhamento e possível intervenção eletrofisiológica. Discussão: No padrão WPW coexistem dois caminhos elétricos para a comunicação atrioventricular (AV), o nodo AV e o feixe de Kent, e ambos serão simultaneamente percorridos pelo estimulo atrial, como consequência, teremos o QRS formado pela fusão dessas duas vias de estimulação. Como a condução é mais rápida pela via acessória do que pelo nodo $\mathrm{AV}$, o estímulo passa instantaneamente para o ventrículo gerando o intervalo PR curto ( $<120 \mathrm{~ms})$ e a onda Delta devido a ativação ventricular precoce. É importante fazer a distinção entre o padrão de WPW e síndrome de WPW. A maioria dos pacientes com o padrão WPW no ECG permanecem assintomáticos. No entanto, uma pequena porcentagem com o padrão de WPW desenvolvem arritmias (fibrilação atrial com resposta ventricular rápida, e taquicardia supraventricular por via acessória), como parte da síndrome de WPW. As indicações para estudo eletrofisiológico (EEF) em pacientes com pacientes assintomáticos com padrão WPW e que não apresentam comorbidades cardíacas seriam para determinar se a via acessória é capaz de suportar uma taquicardia de reentrada e medir as características de condução da via acessória.

\section{Referência:}

Silveria, G.V.; Jornada, F.M.; Tornatore, A.R.; Accorsi, B.F.;. Achado Eletrocardiográfico De Um Paciente Com Padrão WolffParkinson-White. In: II Congresso Brasileiro de Medicina Hospitalar - II CBMH [= Blucher Medical Proceedings, vol.1, num.5] São Paulo: Editora Blucher, 2014. p.43

DOI 10.5151/medpro-II-cbmh-036 